\title{
ANALISIS PENGUATAN MAJELIS PERMUSYAWARATAN RAKYAT SEBAGAI LEMBAGA PARLEMEN DALAM SISTEM KETATANEGARAAN DI INDONESIA
}

\author{
Fatmawati* $^{*}$
}

\begin{abstract}
Abtract
If the theory Montesquie used as a guide, then the power of the executive, legislative, and judicial have an equal footing, but if the theory of separation of powers set forth by John Locke used, then between 3 (three) of power, the legislative power is the supreme power in a state (the supremacy of parliament). After the 1945 changes, in accordance with what was agreed by PAH I MPR, the presidential system of government is emphasized by setting among others concerning the election of President and Vice President directly and the impeachment of President and Vice President by reason of violation of the law. Among the many things that are changing the position and authority of the Assembly in the state system in Indonesia. Although the position of the Assembly after the 1945 changes to be on par with other state agencies, but in the case of termination of the President and Vice President, the Assembly remains as a body breaker if the President and Vice President are eligible for impeached (souvereignty of parliament).
\end{abstract}

Keywords: constitutional system, MPR/DPR, UUD 1945

\begin{abstract}
Abstrak
Apa yang dikemukakan Montesquie dan John Locke maka terdapat perbedaan dalam melaksanakan "pemisahan kekuasaan" dalam sebuah negara. Jika teori Montesquie yang dijadikan pedoman, maka kekuasaan eksekutif, legislative, dan yudisial memiliki kedudukan yang setara, akan tetapi jika teori pemisahan kekuasaan yang dikemukakan oleh John Locke yang digunakan, maka diantara 3 (tiga) kekuasaan, maka kekuasaan legislatif merupakan kekuasaan tertinggi dalam sebuah negara (supremasi parlemen). Setelah perubahan UUD 1945, sesuai dengan
\end{abstract}

* Pengajar Bidang Studi Hukum Tata Negara Fakultas Hukum Universitas Indonesia. Artikel ini berasal dari makalah yang disampaikan pada Kegiatan Pertemuan Ahli (Expert Meeting) yang diselenggarakan Kelompok DPD di MPR, Jakarta, 6 Juni 2010. Alamat kontak: fatmawati_ch@yahoo.com 
apa yang disepakati oleh PAH I MPR, maka sistem pemerintahan presidensil dipertegas dengan mengatur antara lain mengenai pemilihan Presiden dan Wakil Presiden secara langsung dan pemakzulan Presiden dan Wakil Presiden dengan alasan pelanggaran hukum. Diantara berbagai hal yang mengalami perubahan adalah mengenai kedudukan dan kewenangan MPR dalam sistem ketatanegaraan di Indonesia. Walaupun kedudukan MPR setelah perubahan UUD 1945 menjadi setara dengan lembaga negara lainnya, akan tetapi dalam hal pemberhentian Presiden dan Wakil Presiden, MPR tetap sebagai lembaga pemutus apakah Presiden dan Wakil Presiden memenuhi syarat untuk dimakzulkan (souvereignty of parliament).

Kata kunci: sistem ketatanegaraan, MPR/DPR, UUD 1945

\section{Pendahuluan}

Wacana penguatan Majelis Permusyawaratan Rakyat (MPR) pada dasarnya bukan hal yang baru mengingat pada dasarnya dalam UUD Negara Republik Indonesia Tahun 1945 (selanjutnya disingkat UUD 1945) naskah awal, MPR merupakan lembaga penjelmaan seluruh rakyat Indonesia, sebagaimana diatur dalam Pasal 1 ayat (2) UUD 1945 naskah awal, bahwa: "Kedaulatan adalah di tangan rakyat, dan dilakukan sepenuhnya oleh Majelis Permusyawaratan Rakyat". " Hal tersebut dipertegas lagi dalam Penjelasan UUD 1945 bahwa "Kekuasaan Negara yang tertinggi di tangan Majelis Permusyawaratan Rakyat (Die gesamte Staatgewaltliegt bei der Majelis)".2

Sebelum membahas analisis penguatan MPR sebagai lembaga parlemen dalam sistem ketatanegaraan di Indonesia, dibahas terlebih dahulu mengenai argumentasi kedudukan MPR sebagai lembaga negara tertinggi dalam sistem ketatanegaraan di Indonesia sebelum perubahan UUD 1945. Hal tersebut dianggap perlu untuk dibahas, mengingat dasar filosofis MPR sebagai lembaga negara tertinggi, serta kewenangan yang dimiliki oleh MPR sudah mengalami perubahan sesudah diubahnya UUD 1945.

\footnotetext{
${ }^{1}$ Republik Indonesia, Oendang-Oendang Dasar, BRI Tahun II No. 7 Tahun 1946, Pasal 1 ayat (2).

${ }^{2}$ Ibid., Penjelasan.
} 


\section{Analisis Kedudukan MPR Sebagai Lembaga Negara Tertinggi Sebelum Perubahan UUD 1945}

MPR sebagai lembaga negara tertinggi sebelum perubahan UUD 1945 dianalisis kedudukan dan kewenangannya agar diperoleh pemahaman yang menyeluruh mengenai MPR sebelum perubahan UUD 1945 sebagai lembaga negara tertinggi dalam sistem ketatanegaraan di Indonesia sebelum perubahan UUD 1945.

\section{Analisis Kedudukan MPR Sebagai Lembaga Negara Tertinggi Dari Segi Teori Hukum Tata Negara}

Sebelum dikenalnya pemisahan kekuasaan dalam negara, seluruh kekuasaan yang ada dalam negara dilaksanakan oleh raja. Monarki absolut tersebut terjadi di seluruh Eropa. Pemisahan kekuasaan harus dilaksanakan karena sebagaimana yang dikemukakan oleh Montesquieu, bahwa bila kekuasaan legislatif dan eksekutif dipegang oleh satu orang atau oleh sebuah badan, maka tidak akan ada kebebasan karena warga negara akan khawatir jika raja atau senat yang membuat UU bersifat tirani maka UU akan dilaksanakan secara tiran. ${ }^{3}$ Kebebasan pun tidak ada jika kekuasaan yudisial tidak dipisahkan dari kekuasaan legislatif dan kekuasaan eksekutif, maka kekuasaan atas kehidupan dan kebebasan warga negara akan dijalankan sewenang-wenang karena hakim akan menjadi pembuat hukum, dan jika hakim disatukan dengan kekuasaan eksekutif maka hakim bisa menjadi penindas. ${ }^{4}$

Pemikir pertama yang mengemukakan teori mengenai pemisahan kekuasaan dalam negara adalah John Locke dalam bukunya Two Treatises on Civil Government (1690). Pada bab XII buku tersebut yang berjudul the Legislative, Executive and Federative Power of the Commonwealth, Locke memisahkan kekuasaan dalam tiap-tiap negara dalam kekuasaan legislatif, eksekutif, dan federatif. ${ }^{5}$ Kekuasaan legislatif yaitu kekuasaan membuat

${ }^{3}$ Montesquieu, "L'Esprit des Lois, atau The Spirit of Laws", trans. by Thomas Nugent tahun 1752, rev. by J.V. Prichard, (London: G. Bell and Sons, Ltd., 1914), hal. 153-154.

${ }^{4}$ Ibid., hal. 154.

${ }^{5}$ Lihat John Locke, Two Treatises of Government (In the Former, The False Principles and Foundation of Sir Robert Filmer, and His Followers, Are Detected and Overthrown: The Latter, Is an Essay Concerning the Original. Extent, and End, of Civil Government), in ten volume, vol. V, (London: Printed for Thomas Tegg; W. Sharpe and Son; G. Offor; G. and J. Robinson; J. Evans and Co.; Also R. Griffin and Co. Glasgow; and J. Gumming, Dublin, 1823), hal. 167-169. 
undang-undang (UU), ${ }^{6}$ kekuasaan eksekutif, yaitu kekuasaan melaksanakan $\mathrm{UU}^{7}{ }^{7}$ dan kekuasaan federatif, yaitu kekuasaan yang meliputi kekuasaan mengenai perang dan damai, membuat perserikatan dan aliansi serta segala tindakan dengan semua orang dan badan-badan di luar negeri. ${ }^{8}$

150. In all cases whilst government subsists, the legislative is the supreme power. For what can give laws to another must needs be superior to him, and since the legislative is no otherwise legislative of the society but by the right it has to make laws for the all parts, and every member of the society prescribing rules for their action, they are transgressed, the legislative must need be the supreme, and all other powers in any members or parts of the society derived from and subordinate it. ${ }^{9}$

Berdasarkan hal tersebut, maka menurut Locke, kekuasaan legislatif merupakan lembaga yang dipilih dan disetujui oleh warga (chosen and appointed), berwenang membuat UU dan merupakan kekuasaan tertinggi dalam sebuah negara.

Diilhami oleh pendapat John Locke, Charles-Louis de Secondat, Baron de Montesquieu dalam bukunya The Spirit of Laws (1748), pada bab XI menulis tentang Konstitusi Inggris. Montesquieu memisahkan 3 (tiga) jenis kekuasaan, yaitu kekuasaan legislatif, kekuasaan eksekutif dan kekuasaan yudisial. Kekuasaan legislatif memiliki kekuasaan membuat UU, dan mengubah atau menghapus UU; kekuasaan eksekutif memiliki kekuasaan menyatakan perang atau damai, mengirimkan atau menerima duta, menjamin keamanan umum serta menghalau musuh yang masuk; sedangkan kekuasaan yudisial memiliki kekuasaan menghukum para penjahat atau memutuskan perselisihan yang timbul di antara orang perseorangan. ${ }^{10}$ Berbeda dengan John Locke yang other hands....

${ }^{6}$ Ibid., hal 167. "141. ... The legislative can not transfer the power of making laws to any

143. The legislative power is that which has a right to direct how the force of the commonwealth shall be employed for preserving the community and the members of it."

${ }^{7}$ Ibid., hal. 168.

${ }^{8}$ Ibid.

${ }^{9}$ Ibid., hal. 170. 
memasukkan kekuasaan yudisial dalam kekuasaan eksekutif, Montesquieu memandang kekuasaan yudisial sebagai kekuasaan yang berdiri sendiri. ${ }^{11}$

Menurut Montesquieu, pada negara yang merdeka, seharusnya kekuasaan legislatif dilaksanakan oleh seluruh rakyat, akan tetapi itu tidak mungkin dilaksanakan pada negara yang wilayahnya luas, bahkan akan banyak ditemui kesulitan jika dilakukan di negara yang wilayahnya dianggap kecil sekalipun; hal tersebut menyebabkan rakyat harus diwakili. ${ }^{12}$

Montesquieu menyatakan bahwa dalam masyarakat, selalu ada segolongan yang berbeda dikarenakan kelahiran, kekayaan, atau status sosial, sehingga memiliki kepentingan yang juga berbeda dari masyarakat umumnya. ${ }^{13}$ Oleh karena itu, kamar dalam parlemen tidak hanya berisikan wakil rakyat yang dipilih berdasarkan pembagian wilayah tertentu (distrik), tetapi juga berisikan para bangsawan.

The legislative power is therefore committed to the body of the nobles, and to that which represents the people, each having their assemblies and deliberation apart, each their separate views and interests. $^{14}$

Struktur parlemen terdiri dari 2 (dua) bagian, yang saling mengawasi satu sama lain, dan memiliki keistimewaan yang sama (mutual previlege) untuk saling menolak RUU yang diajukan oleh kamar yang lain. ${ }^{15}$ Kamar yang berisikan bangsawan, rekruitmennya didasarkan atas keturunan, dan kewenangan mereka hanya sebatas menolak RUU yang diajukan oleh kamar yang diwakili oleh rakyat pada umumnya. ${ }^{16}$ Anggota parlemen yang bukan merupakan bangsawan dipilih oleh setiap warga negara dalam lingkup wilayah

\footnotetext{
${ }^{10}$ Ibid., hal. 153.

${ }^{11}$ Ibid., hal. 154.

${ }^{12}$ Ibid., hal. 155.

${ }^{13}$ Ibid., hal. 156-157.

${ }^{14}$ Ibid., hal. 157.

${ }^{15}$ Ibid., hal. 160.

${ }^{16}$ Ibid., hal. 157.
} 
tertentu (distrik) oleh para warga negara pada daerah tersebut karena mereka lebih mengetahui tentang calon anggota parlemen tersebut. ${ }^{17}$

Berdasarkan apa yang dikemukakan oleh kedua ahli tersebut, maka terdapat perbedaan dalam melaksanakan "pemisahan kekuasaan" dalam sebuah negara. Jika teori Montesquieu yang dijadikan pedoman maka kekuasaan eksekutif, legislative, dan yudisial memiliki kedudukan yang setara, akan tetapi jika teori pemisahan kekuasaan yang dikemukakan oleh John Locke yang digunakan, maka diantara 3 (tiga) kekuasaan, maka kekuasaan legislatif merupakan kekuasaan tertinggi dalam sebuah negara (supremasi parlemen).

\section{Analisis Kedudukan MPR Sebagai Lembaga Negara Tertinggi Dari Segi Historis}

Penyusun UUD 1945 mengemukakan bahwa UUD yang dibahas menggunakan "sistem sendiri" sebagaimana dikemukakan oleh Soekiman dan Soepomo, yaitu:

\section{SOEKIMAN IIN: ...}

Syahdan setelah mempelajari dengan seksama rancangan undang-undang dasar negara kita tadi, maka sebagai kesimpulan terakhir saya menyatakan bahasa rancangan ini bersistem sendiri berbeda dengan sistem undang-undang beberapa negara yang terkemuka. Indonesia ini seperti Dai Nippon, Amerika, Rusland, prans dan lain-lainnya. Ini menjadi kekuatannya menurut hemat saya, karena didalamnya dapatlah digunakan pengalaman-pengalaman yang baik daripada sistem-sistem negara tersebut tadi, misalnya: oleh karena negara Indonesia berbentuk republik, maka kedaulatan rakyat harus diakui sebagai azas pemerintahannya. Menilik tingkat kecerdasan rakyat kita, maka buat sementara waktu kedaulatan rakyat yang tadi baru kita wujudkan, jelaskan dalam satu badan saja dulu, yang dinamakan Majelis Permusyawaratan Rakyat, pasal 17 bab 6, yang sedikitnya sekali dalam 5 tahun, bersidang untuk:

1. memilih Presiden dan Wakil Presiden,

2. untuk menetapkan undang-undang dasar dan garis-garis besar dari pada haluan negara (Pasal 18).

${ }^{17}$ Ibid., hal. 156. 
Untuk lebih menegaskan kedaulatan Majelis Permusyawaratan Rakyat, maka saya mengusulkan, supaya ditetapkan dalam undang-undang dasar ini, bahwa prinsip pemilihan Majelis Permusyawaratan Rakyat harus langsung oleh rakyat. Jadi saya usulkan supaya pemilihan Majelis Permusyawaratan Rakyat sebagai prinsip dipilih langsung oleh rakyat. Dalam pemandangan saya maka kedaulatan Majelis Permusyawaratan itu paling sedikit sama kedudukannya dengan Rijksdag Jerman, Konstitusi Weimar, Majelis Rendah Dai Nippon atau Tweede Kamer dari Staaten Generaal Belanda, pemilihan badan-badan perwakilan mana ditetapkan oleh undang-undang dasar masing-masing negeri itu langsung oleh rakyat (konstitusi Jerman Art. 22 Konstitusi Dai Nippon Art. 35, Belanda art 83-84) karena Majelis Permusyawaratan Rakyat ini tidak dapat dibubarkan dalam bentukan konstruksi rancangan ini, maka Dewan Perwakilan Rakyat mempunyai kedudukan lebih rendah daripada Majelis Permusyawaratan Rakyat, karena pekerjaannya itu membikin undang-undang biasa, organieke wet (pasal 20-21). Supaya ada sedikit garis atau sistem yang praktis. Pada perkara kekuasaan kedaulatan rakyat, maka saya mengusulkan supaya Dewan Perwakilan Rakyat disusun oleh dan daripada anggota Majelis Permusyawaratan Rakyat, menjadi 2 badanlah yang menjadi mandataris atau kuasa kedaulatan rakyat, yakni Presiden dan Dewan Perwakilan Rakyat untuk menyingkirkan keadaan keruh yang yang mungkin timbul dalam perjuangan pemilihan dan menilik tingkat kecerdasan rakyat kita, maka saya mufakat sekali Presiden dipilih oleh Majelis Permusyawaratan Rakyat (pasal 4), dan buat sementara langsung tidak dipilih oleh rakyat, buat sementara dengan kedudukan Presiden sebagai pembikin undang-undang biasa bersama dengan Dewan Perwakilan Rakyat dan para Menteri-menteri bertanggungjawab kepadanya, tidak kepada Dewan Perwakilan Rakyat, maka pemerintah secara parlementaire demokrasi Eropah tidak terpakai, yang saya sendiri amat setuju (pasal 3). Dengan konstruksi demikian, maka terjaminlah tetap langsung stabiliteit pemerintahan yang sungguh menjadi syarat mutlak untuk membuat negara baru. ${ }^{18}$

18 A.B. Kusuma, "Lahirnya Undang-Undang Dasar 1945 (Memuat Salinan Dokumen Otentik Badan Oentoek Menyelidiki Oesaha2 Persiapan Kemerdekaan)", (Jakarta: Badan Penerbit Fakultas Hukum UI, 2004), hal. 374-375. Lihat pula Saafroedin Bahar, Ananda B. Kusuma, Nannie Hudawati eds., "Risalah Sidang Badan Penyelenggara Usaha Persiapan Kemerdekaan Indonesia (BPUPKI)Panitia Persiapan Kemerdekaan Indonesia (PPKI) 28 Mei 1945-22 Agustus 1945", ed. III, cet. 2, (Jakarta: Sekretariat Negara R.I., 1995), hal. 285-287. 
SOEPOMO IIN: Paduka tuan Ketua, sekarang tentang sistem negara...

Kita memakai sistem sendiri sebagai dikatakan oleh tuan Soekiman, sistem itu ialah kepala negara yang tidak tunduk kepada Badan Perwakilan Rakyat, akan tetapi ia bertanggung jawab sepenuh - penuhnya kepada Majelis Permusyawaratan Rakyat yang tiap - tiap 5 tahun bersidang dan dalam pada waktu itu sudah tentu akan terang apakah haluan yang akan dijalankan oleh Pemerintah disetujui atau tidak oleh Majelis Permusyawaratan Rakyat. Menteri - menteri juga hanya tunduk kepada Kepala Negara. ${ }^{19}$

Dapat dibuat dalam beberapa poin, apa yang dikemukakan oleh ketua dan anggota Panitia Kecil Perancang UUD ${ }^{20}$ tersebut, yaitu:

1. Supremasi MPR, dimana MPR merupakan perwujudan kedaulatan rakyat.

2. MPR berwenang memilih Presiden dan Wakil Presiden, menetapkan UUD dan garis-garis besar dari pada haluan negara.

3. Presiden dan Wakil Presiden bertanggung jawab kepada MPR dan menjalankan pemerintahan berdasarkan haluan negara yang disetujui oleh MPR.

4. MPR dipilih langsung oleh rakyat. ${ }^{21}$

19 A.B. Kusuma, Ibid., hal. 389. Lihat pula Saafroedin Bahar, Ananda B. Kusuma, Nannie Hudawati eds., Ibid., hal. 304.

${ }^{20}$ Panitia Kecil Perancang UUD terdiri dari Wongsonagoro, Soebardjo, Maramis, Soekiman, Salim, dan Soepomo sebagai Ketua. Lihat A.B. Kusuma, Ibid., hal. 312. Lihat pula Saafroedin Bahar, Ananda B. Kusuma, Nannie Hudawati eds., Ibid., hal.222. Dalam rapat tersebut, diusulkan agar Yamin dapat menjadi anggota Panitia Hukum Dasar, akan tetapi surat dari Panitia Hukum Dasar tentang Yamin tersebut, ditolak oleh Ketua BPUPK.

${ }^{21}$ Mengenai MPR dipilih langsung oleh rakyat dikemukakan dalam rapat BPUK tanggal 15 Juli 1945, selain dikemukakan oleh Soekiman, juga dikemukakan oleh Soepomo (A.B. Kusuma, Ibid., hal. 377. Lihat pula Saafroedin Bahar, Ananda B. Kusuma, Nannie Hudawati eds., Ibid., hal. 289.) Dari jawaban Soepomo tersebut, ditanggapi oleh Hatta bahwa "Kalau organis tidak bisa langsung." Akan tetapi Ketua BPUPK (Radjiman) menegaskan bahwa pemilihannya harus langsung (algemene kiesrecht).

"SOEPOMO IIN: Pertama soal dari tuan Soekiman terhadap cara pemilihan Majelis Permusyawaratan Rakyat dan cara Dewan Perwakilan Rakyat panitia tetap berpendirian cara itu lebih baik diatur dalam undang-undang, tidak dimasukkan dalam undang-undang dasar. Karena tadi dikemukakan undang-undang dasar disebut sesupel-supelnya, memuat aturan-aturan yang pokok; yang diuraikan itu sudah tentu sudah tercatat dalam perslag dalam pembicaraan hari ini. Ini tentu akan diperingati kemudian kalau membentuk undang-undang...." (A.B. Kusuma, Ibid., hal. 376. Lihat pula Saafroedin Bahar, Ananda B. Kusuma, Nannie Hudawati eds., Ibid., hal. 288). 
5. DPR berwenang sebagai pembentuk UU, bersama-sama dengan Presiden.

6. Para menteri bertanggung jawab kepada Presiden, bukan kepada DPR.

Jika dibandingkan dengan teori pemisahan kekuasaan yang dikemukakan John Locke, maka terdapat kesamaan dalam hal supremasi terletak pada parlemen dan dalam pembentukan UU, kekuasaan eksekutif ikut membahas dan menyetujui UU. ${ }^{22}$ Argumentasi dari hal tersebut dikemukakan oleh Walter Bagehot, yaitu bahwa jika yang harus melakukan pekerjaan tidak sama dengan yang membuat UU, maka akan ada kontroversi antara kedua kelompok. ${ }^{23}$

Menurut Harun Alrasyid, secara institusional, organ-organ negara yang tercantum dalam UUD 1945 dapat dikatakan merupakan kelanjutan dari organorgan negara kolonial yang tercantum dalam IS (Indische Staatsregelling), dan MPR merupakan pengganti Raja Belanda.

Memang, ditinjau secara institusional, organ-organ negara yang tercantum dalam undang-undang dasar dapat dikatakan merupakan kelanjutan dari organorgan negara kolonial yang tercantum dalam Indische Staatsregelling:

- "Gouverneur Generaal" diganti dengan Presiden;

- "Luitenant-Gouverneur Generaal" diganti dengan Wakil Presiden;

"SOEKIMAN IIN: Tentang azasnya dalam undang-undang Hukum di dapat juga, bahwa perwakilan itu harus langsung dipilih oleh rakyat. Cuma pernyataan itu saja yang hendak saya masukkan dalam grondwet. Majelis Permusyawaratan Rakyat pemilihannya jangan hanya dengan undang-undang, tetapi diterangkan sebagai azas harus langsung dari rakyat." (A.B. Kusuma, Ibid., hal. 377. Lihat pula Saafroedin Bahar, Ananda B. Kusuma, Nannie Hudawati eds., Ibid., hal. 289.)

"SOEPOMO IIN: Sebagai prinsip dasar itu saya sendiri tidak keberatan. Jadi dalam pasal 17: "Majelis Permusyawaratan Rakyat terjadi atas anggota dewan ditambah dengan utusan-utusan dari daerah dan golongan menurut aturan yang ditetapkan dengan undang-undang". Cara pemilihan langsung telah ada." (A.B. Kusuma, Ibid. Lihat pula Saafroedin Bahar, Ananda B. Kusuma, Nannie Hudawati eds., Ibid.)

"RADJIMAN KAITYOO: "Algemene Kiesrecht." (A.B. Kusuma, Ibid. Lihat pula Saafroedin Bahar, Ananda B. Kusuma, Nannie Hudawati eds., Ibid.).

Selain itu juga, bahwa MPR dipilih langsung oleh rakyat dikemukakan oleh Yamin (A.B. Kusuma, Ibid., hal. 380-382. Lihat pula Saafroedin Bahar, Ananda B. Kusuma, Nannie Hudawati, eds., Ibid., hal. 293-295.)

${ }^{22}$ Lihat John Locke, Op. Cit., hal. 170.

${ }^{23}$ Walter Bagehot, "The English Constitution: The Cabinet", dalam Arend Lijphart, ed., "Parliamentary versus Presidensial Government", reprinted, (New York: Oxford University Press, 2004), hal. 67. 
- "Directeur van een departement" diganti dengan Menteri;

- "Raad van nederlands-Indie" diganti dengan Dewan Pertimbangan Agung;

- "Volksraad" diganti dengan Dewan Perwakilan Rakyat;

- "Algemene Rekenkamer" diganti dengan Badan Pemeriksa Keuangan;

- "Hoogerechtshof" diganti dengan Mahkamah Agung.

Timbul persoalan yang harus dipecahkan oleh bapak-bapak kita yang menyusun undang-undang dasar (The Fathers of the Contitution): siapakah yang akan menggantikan Raja Belanda yang dulu berkedudukan sebagai "opperbestuur" kepada siapa Gubernur Jenderal harus memberikan pertanggungan jawab mengenai pelaksanaan tugas dan wewenangnya?

Untuk memecahkan persoalan tersebut, diciptakanlah majelis Permusyawaratan rakyat kepada siapa Presiden bertanggung jawab. Memang soal pertanggungjawaban dalam sistematik formal hukum tata negara positif, merupakan segi khusus dari hubungan kewibawaan. ${ }^{24}$

Apa yang dikemukakan Harun Alrasid tidak sesuai dengan pembahasan tentang hal tersebut dalam sidang-sidang BPUPK (Badan Pemeriksa Usaha Persiapan Kemerdekaan). ${ }^{25}$ Sebagaimana dikemukakan oleh Soekiman dan Soepomo, sistem yang digunakan dalam UUD 1945 adalah sistem sendiri, dan jika memang MPR adalah pengganti dari Raja Belanda, tentu Hatta tidak akan meminta agar dibahas dahulu secara mendalam usulan dari Soetardjo agar dalam Pasal 6 ayat (2) ditambahkan bahwa MPR berwenang memberhentikan Presiden dan Wakil Presiden. ${ }^{26}$ Soepomo juga sangat memahami bahwa dalam negara demokrasi, eksekutif harus bertanggungjawab kepada legislatif, sehingga sangat tidak mungkin MPR dianggap padanan dari Ratu Belanda. ${ }^{27}$

${ }^{24}$ Harun Alrasid, "Majelis Permusyawaratan Rakyat (Pelaku Kedaulatan Rakyat)", dalam A. Muhammad Asrun, ed., "70 Tahun Ismail Suny Bergelut dengan Ilmu, Berkiprah dalam Politik", (Jakarta: Pustaka Sinar Harapan, 2000), hal. 175-176.

${ }^{25}$ Pada saat itu, belum dipergunakan istilah Indonesia, akan tetapi Hindia Timur, atau To Indo. Lihat A.G. Pringgodigdo, "Sedjarah Singkat Berdirinja Negara Republik Indonesia", cet I, (Surabaya: N.V. Pustaka Indonesia, 1958), hal. 24.

${ }^{26}$ A.B. Kusuma, Op. Cit., hal. 469. Lihat pula Saafroedin Bahar, Ananda B. Kusuma, Nannie Hudawati eds., O.p Cit., hal. 413. 


\section{Analisis Kedudukan MPR Sebagai Lembaga Negara Tertinggi Dari Segi Perbandingan Hukum Tata Negara}

MPR dalam UUD 1945 sebelum perubahan merupakan lembaga negara tertinggi, dan dalam prakteknya ternyata tidak hanya Indonesia yang menggunakan Supremacy of Parliament, tetapi juga negara lainnya, antara lain Inggris, India, Belanda, Ethiopia, ${ }^{28}$ dan Jepang, ${ }^{29}$

\section{Analisis Penguatan MPR Sebagai Lembaga Parlemen Dalam Sistem Ketatanegaraan di Indonesia}

Beberapa hal yang perlu didiskusikan lebih lanjut mengenai hal ini, antara lain adalah pernyataan bahwa sebelum perubahan UUD 1945, UUD 1945 menggunakan sistem pemerintahan presidensil dan perbandingan kewenangan MPR dengan kewenangan kamar/majelis ketiga lainnya di beberapa negara.

\section{Pernyataan Bahwa Sebelum Perubahan UUD 1945, UUD 1945 Menggunakan Sistem Pemerintahan Presidensil}

${ }^{27}$ Ananda B. Kusuma, Presidensialisme ala Indonesia, disampaikan dalam "Diskusi Publik Wacana Amandemen UUD 1945", yang diselenggarakan oleh Komisi Hukum Nasional RI, Hotel Millenium, 15 Mei 2008, hal. 20.

${ }^{28}$ Constitution of the Federal Democratic Republic of Ethiopia sebagaimana dikutip dalam Jimly Asshiddiqie, et. al., ed., "Kompilasi Konstitusi Sedunia", buku 2, (Jakarta: Pusat Penelitian dan Pengkajian Sekretariat Jenderal dan Kepaniteraan Mahkamah Konstitusi Republik Indonesia, 2005), hal. 805. Dalam Article 50 ayat (3) Constitution of The Federal Democratic Republic of Ethiopia diatur bahwa: "The House of Peoples' Representatives is the highest authority of the Federal Government. The House is responsible to the People...."

${ }^{29}$ Glenn D Hook dan Gavan Mc Cormack, "Japan's Contested Constitution: Document and Analysis", (London: Routledge, 2001), hal. 194. Article 41 The Constitution of Japan mengatur sebagai berikut: "The Diet shall be the highest organ of state power, and shall be the sole law-making organ of the State." 
Dalam melakukan perubahan terhadap UUD 1945, Panitia Ad Hoc (PAH) I MPR menyusun kesepakatan dasar berkaitan dengan perubahan UUD 1945, yaitu:

1. tidak mengubah Pembukaan Undang-Undang Dasar Negara Republik Indonesia Tahun 1945;

2. tetap mempertahankan Negara Kesatuan Republik Indonesia;

3. mempertegas sistem pemerintahan presidensial;

4. Penjelasan Undang-Undang Dasar Negara Republik Indonesia Tahun 1945 yang memuat hal-hal normatif akan dimasukkan ke dalam pasalpasal (Batang Tubuh)

5. melakukan perubahan dengan cara adendum. ${ }^{30}$

Sebagaimana telah dikemukakan sebelumnya bahwa UUD 1945 menggunakan sistem sendiri. Dalam hal sistem pemerintahan yang digunakan dalam UUD 1945, A.B. Kusuma mengemukakan bahwa para penyusun UUD 1945 membuat sistem pemerintahan sendiri, yang mendapat ilham dari Inggris yang mempunyai lembaga tertinggi yang supreme tempat kedaulatan rakyat (locus of sovereignty), akan tetapi penyusun UUD 1945 melihat bahwa sistem Inggris memungkinkan terjadinya pemerintahan yang bersifat diktatur bila partai dari Perdana Menteri mendapat kemenangan besar, sebab itu hanya bagian baik saja yang digunakan; selain itu, penyusun UUD 1945 pemerintahan yang selalu berganti, hingga mengambil dari Amerika tentang fixed government. ${ }^{31}$

Setelah perubahan UUD 1945, sesuai dengan apa yang disepakati oleh PAH I MPR, maka sistem pemerintahan presidensil dipertegas dengan mengatur antara lain mengenai pemilihan Presiden dan Wakil Presiden secara langsung $^{32}$ dan pemakzulan Presiden dan Wakil Presiden dengan alasan pelanggaran hukum. ${ }^{33}$ Akan tetapi, apakah saat ini yang digunakan adalah

${ }^{30}$ Sekretariat Jenderal MPR-RI, "Panduan Dalam Memasyarakatkan Undang-Undang Dasar Negara Republik Indonesia Tahun 1945: Latar Belakang, Proses, dan Hasil Perubahan UndangUndang Dasar Negara Republik Indonesia Tahun 1945 Sesuai dengan Urutan Bab, Pasal, dan Ayat", (Jakarta: Sekretariat Jenderal MPR-RI, 2007), hal. 13.

${ }^{31}$ Lihat A.B. Kusuma, Lahirnya..., op cit., hal. 38-39.

32 Lihat Republik Indonesia, Perubahan Ketiga Undang-Undang Dasar Negara Republik Indonesia Tahun 1945, LN No. 13, LN Tahun 2006, Pasal 6A ayat (1). 
sistem presidensil? Hal tersebut harus dianalis lebih lanjut karena jika konsisten menggunakan separation of powers sebagaimana yang dikemukakan oleh Montesquieu, maka eksekutif hanya memiliki hak veto ${ }^{34}$ dan tidak ikut membahas dalam rangka mencapai persetujuan sebagaimana separation of powers yang dikemukakan oleh John Locke. ${ }^{35}$

Berkaitan dengan separation of powers antara eksekutif dan legislatif, dikemukakan oleh Arend Lijphart bahwa salah satu dari karakteristik penting yang membedakan antara sistem pemerintahan presidensil dan sistem pemerintahan parlementer adalah pemisahan antara kekuasaan eksekutif dan kekuasaan legislatif. ${ }^{36} \mathrm{Hal}$ tersebut juga dikemukakan oleh Paul Christopher Manuel dan Anne Maria Camissa, dimana karakteristik utama dari sistem presidensial adalah pemisahan kekuasaan legislatif dan kekuasaan eksekutif. ${ }^{37}$ Dalam UUD 1945 diatur bahwa setiap RUU dibahas oleh DPR dan Presiden untuk mendapat persetujuan bersama. ${ }^{38}$

\section{Perbandingan Kewenangan MPR Dengan Kewenangan Kamar/Majelis Ketiga Lainnya Di Berbagai Negara}

Pendekatan adendum dijadikan kesepakatan bersama, akan tetapi dari apa yang dikemukakan anggota MPR, terutama anggota MPR yang menjadi Panitia

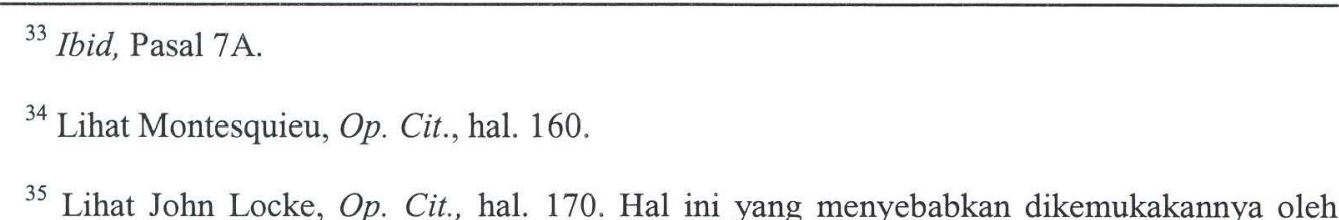
Bagir Manan bahwa dalam perubahan UUD 1945 belum terdapat separation of powers akan tetap distribution of powers dan mencerminkan pula kekuasaan membentuk UU dilakukan bersama-sama oleh DPR dan Presiden, dengan mengemukakan contoh separation of powers di Amerika Serikat yang UUD-nya mengatur: "all legislative powers herein granted shall be vested in a Congress of the United States, which shall consist of a Senate and House Representatives." Lihat Bagir Manan, DPR, DPD dan MPR dalam UUD 1945 Baru. cet. 2, (Yogyakarta: FH UII Press, 2004), hal. 24.

${ }^{36}$ Lihat Arend Lijphart, "Democracy: Patterns of Majoritarian and Consensus Government in Twenty-One Countries", (New Haven and London: Yale University Press, 1984), hal. 68.

${ }^{37}$ Lihat Paul Christopher Manuel dan Anne Maria Camissa, "Checks and Balances? How a Parliamentary System Could Change American Politics", (United States of America: Westview Press, 1999), hal. 16.

${ }^{38}$ Lihat Republik Indonesia, Perubahan Pertama Undang-Undang Dasar Negara Republik Indonesia Tahun 1945, LN No. 11, LN Tahun 2006, Pasal 20 ayat (2). 
Ad Hoc, ternyata bukan perubahan akan tetapi penggantian. Sebagian besar anggota PAH yang ditugaskan menyusun perubahan UUD 1945 menginginkan agar UUD 1945 tidak dijadikan landasan dalam melakukan perubahan, ${ }^{39}$ walaupun tetap ada anggota MPR yang berpendapat sebaliknya. ${ }^{40}$ Penggantian dan bukan perubahan tersebut, dikemukakan oleh Hendy Tjaswadi (FTNI/POLRI) dalam Pandangan Akhir Fraksi terhadap Hasil Finalisasi Perubahan Kedua UUD 1945..$^{41}$ Para ahli juga mengemukakan bahwa yang dilakukan bukan lagi merupakan adendum. ${ }^{42}$

39 Asnawi Latief (Fraksi Partai Daulatul Umah) mengemukakan bahwa amandemen menyangkut penyempurnaan, penghapusan, dan penambahan. Lihat Sekretariat Jenderal MPR-RI, Risalah Rapat Ke-10 Panitia Ad Hock I BP MPR 17 Desember 2000, hal. 37. Gregorius Seto Harsanto (Fraksi Partai Demokrasi Kasih Bangsa) mengemukakan bahwa para anggota MPR yang sedang melakukan amandemen hendaknya jika ingin melakukan amademen, tidak terikat dengan interpretasi lama. Sekretariat Jenderal MPR-RI, Risalah Rapat Ke-1 Panitia Ad Hock III BP MPR 7 Oktober 1999, Nomor MJ 230/3/99, hal. 41. Hal serupa juga dikemukakan oleh Slamet Effendi Yusuf (F-PG) dalam Rapat tanggal 10 Oktober 1999 menanggapi apa yang dikemukakan oleh Aberson Marlesihaloho (F-PDI-P), bahwa para anggota PAH III sudah sepakat bahwa dalam melakukan amandemen harus sesuai dengan sistem yang ada dalam UUD 1945. Sekretariat Jenderal MPR-RI, Risalah Rapat Ke-4 Panitia Ad Hock III BP MPR 10 Oktober 1999, Nomor MJ 230/9/99, hal. 23. "...sikap Partai Golkar ketika melakukan Amandemen ini. Jadi kita membangun sistem yang bukan diikat oleh masalah pikiran masalah apa misalnya memang sangat hebat pemikirannya Pah Supomo yang sangat menguasai teritori hukum dan kenegaraan. Tetapi perkembangan-perkembangan ini semua yang dihadapi bangsa memerlukan pikiran-pikiran baru itu yang harus kita urai dan tidak boleh kita lalu menjadi begitu terikat dan sakral penjelasan itu, lalu sesuatunya harus kembalikembali kesana gitu loh.." Valina Singka (Fraksi Utusan Golongan) bahkan dengan tegas bahwa amandemen dilakukan karena batang tubuh UUD 1945 sudah tidak sejalan dengan perkembangan jaman menghadapi abad ke-21. Sekretariat Jenderal MPR-RI, Risalah Rapat Ke-6 Panitia Ad Hock III BP MPR 13 Oktober 1999, Nomor MJ 230/13/99, hal. 13.

${ }^{40}$ Aberson Marle Sihaloho (Fraksi Partai Demokrasi Indonesia Perjuangan) mengemukakan, bahwa para anggota PAH III sudah sepakat bahwa dalam melakukan amandemen harus sesuai dengan sistem yang ada dalam UUD 1945. Sekretariat Jenderal MPR-RI, Risalah Rapat Ke-2 Panitia Ad Hock III BP MPR 8 Oktober 1999, Nomor MJ 230/5/99, hal. 19. Baharudin Aritonang (F-PG) juga mengungkapkan bahwa: "Kalau tata cara amandemen atau merubah UUD 1945 kita tetap bersandar kepada UUD 1945 naskah aslinya, kemudian amandemennya kita usahakan, kemudian lembaran berikutnya. Jadi artinya strukturnya kemudian saya lebih sepakat masih tetap mengikuti struktur atau alur berpikir yang lama, kalau itu memang kesepakatan ini masih kita pegang." Sekretariat Jenderal MPR-RI, Risalah Rapat Ke-8 BP MPR 14 Desember 2000, hal. 15.

${ }^{41}$ Sekretariat Jenderal MPR-RI, Risalah Rapat Ke-51 Panitia Ad Hock I BP MPR 29 Juli 2000, hal. 69. "Perubahan terhadap Undang-Undang Dasar 1945 sebagaimana diamanatkan oleh Pasal 37 Undang-Undang Dasar 1945, mempunyai sifat, ciri-ciri tertentu yang berbeda dengan 
Diantara berbagai hal yang mengalami perubahan adalah mengenai kedudukan dan kewenangan MPR dalam sistem ketatanegaraan di Indonesia. Walaupun kedudukan MPR setelah perubahan UUD 1945 menjadi setara dengan lembaga negara lainnya, akan tetapi dalam hal pemberhentian Presiden dan Wakil Presiden, MPR tetap sebagai lembaga pemutus apakah Presiden dan Wakil Presiden memenuhi syarat untuk dimakzulkan (souvereignty of parliament).

Setelah perubahan UUD 1945, bila MPR sebagai salah satu kamar/majelis dalam Parlemen RI dibandingkan dengan negara yang juga menggunakan sistem multikameral, yaitu yang menggunakan sistem trikameral dan pentakameral (5 kamar/majelis) maka akan terlihat bahwa kedudukan dan kewenangan MPR bukan merupakan hal yang tidak lazim. Jika hanya membandingkan berdasarkan pada pembagian bahwa kamar ketiga mewakili kategori warga negara yang berbeda dari kamar pertama dan kamar kedua, kamar ketiga pada negara-negara tertentu tersebut memiliki fungsi khusus yang dilakukan secara terus menerus, dan kamar ketiga merupakan lembaga negara

penggantian terhadap Undang-Undang Dasar. Batas antara perubahan Undang-Undang Dasar dan penggantian Undang- Undang Dasar sangat tipis bisa diperdebatkan baik mengenai substansi maupun kualitas dan kuantitas dari perubahan atau penggantian tersebut.

Namun demikian perubahan atau penggantian dapat kita bedakan dengan melihat kepada semangat dan wacana yang berkembang pada saat pembahasan berlangsung. Kami berpendapat bahwa substansi perubahan sudah menyentuh ke area penggantian Undang-Undang Dasar."

${ }^{42}$ Ismail Suny mengemukakan: "Bahwa melihat hasil pekerjaan saudara-saudara di dalam perubahan pertama dan perubahan kedua UUD, secara ilmu pengetahuan ini tidak bisa lagi disebut sebagai adendum. Oleh karena adendum itu tidak sebanyak yang telah kita lakukan, apabila keputusan-keputusan yang sudah kami bicarakan ini akan merupakan adendum yang ketiga. Maka akan menjadi perubahan ketiga UUD, ini akan sukar kita menyebut sebagai adendum. Maka yang hidup di dalam diskusi-diskusi itu, kami tawarkan kepada PAH I, kita membuat UUD Republik Indonesia. Yang artinya itu UUD yang baru, sebab kita berpendapat, tidak ada apa yang telah disebut di Indonesia ini, rumah suci, tetapi yang sangat penting bagi Pembukaan Undang-undang Dasar Negara Kesatuan itu akan kita masukkan tetapi yang lain itu, bisa kita rubah jika kepentingan kita sekarang dan di masa depan menghendakinya." Sekretariat Jenderal MPR-RI, Risalah Rapat Pleno Ke-11 Panitia Ad Hock I BP MPR 20 Maret 2001, Nomor MJ 230/11/2001, hal. 3-4. Maswadi Rauf juga mengemukakan hal yang serupa, yaitu: "...bahwa yang akan kita lakukan ini sebenarnya lebih luas dari adendum akan tetapi seperti amanden pertama dan kedua itu kami kira juga bukan adendum, tetapi membentuk sejumlah pasal baru, menambahkan pemikiran-pemikiran baru, merombak bab dan kemudian menjadikan bab itu bab baru, menambah pasal baru sama sekali sehingga kita berkesimpulan bahwa sesuai dengan itu kita akan melakukan rewriting, menulis ulang kembali konstitusi itu dengan memasukkan hal-hal yang kami anggap itu perlu jadi masukkan yang akan menjadi pertimbangan dari PAH I ini.." Ibid., hal. 6-7. 
tertinggi, maka MPR sebagai kamar ketiga merupakan hal yang anomali karena MPR sebagai sebuah kamar/majelis tidak memiliki kebutuhan khusus untuk menjadi lembaga yang permanen. ${ }^{43}$ Hal tersebut disebabkan MPR tidak memiliki semua hal tersebut yaitu mewakili kategori warga negara yang berbeda dari kamar pertama dan kamar kedua, memiliki fungsi khusus yang dilakukan secara terus menerus, dan merupakan lembaga negara tertinggi. Akan tetapi selain hal tersebut, hal lainnya adalah bahwa kamar ketiga pada beberapa negara yang menggunakan sistem multikameral memiliki fungsi khusus yaitu sebagai konstituante dan lembaga pemutus pemakzulan Presiden dan Wakil Presiden.

Negara yang mengatur bahwa kamar ketiganya memiliki fungsi yang bukan merupakan hal yang rutin, akan tetapi merupakan fungsi khusus bagian kamar ketiga adalah the Republic of China 1946 (sebelum amandemen tahun 1994) dan the Islamic Republic of Afghanistan.

Kewenangan formal National Assembly yang diatur dalam Constitution of the Republic of China adalah sebagai berikut:

(1) Memilih Presiden dan Wakil Presiden;

${ }^{43}$ Lihat Fatmawati, Catatan Singkat Mengenai Kedudukan MPR Sesudah Perubahan UUD 1945, Jurnal Hukum dan Pembangunan, Tahun ke-39, Nomor 4, Oktober 2009: 503-504.

Negara-negara yang mewakili kategori warga negara yang berbeda dari kamar pertama dan kamar kedua adalah pada Constitutions of the Republic of South Africa Act 110 of 1983, pemilih yang berkulit putih (white person) memilih untuk anggota House of Assembly, pemilih berkulit berwarna (coloured person) memilih untuk anggota House of Representatives, dan pemilih India memilih untuk anggota House of Delegates, sedangkan dalam Constitution of the Socialist Federal Republic of Yugoslavia (1963) diatur bahwa Federal Assembly terdiri dari 5 kamar yaitu Federal Chamber, Economic Chamber, Chamber of Education and Culture, Chamber of Social Welfare and Health, dan Organizational-Political Chamber. Dalam hal kamar ketiga melaksanakan fungsi khusus yang dilakukan secara terus menerus, terlihat dalam Constitution of the Republic of China 1946 (sebelum revisi tahun 1994) terdapat 3 lembaga yang memiliki fungsi parlemen, yaitu National Assembly, Legislative Yuan, dan Control Yuan. Dari ketiga kamar tersebut, hanya Legislative Yuan yang berwenang membentuk UU, sedangkan fungsi Control Yuan sebagai kamar ketiga, antara lain adalah sebagai pengawas tertinggi, pemberi persetujuan dalam pengangkatan dan pemberhentian pejabat, serta melakukan audit.

Kamar ketiga merupakan lembaga negara tertinggi, terdapat pada kamar ketiga (Loya Jirga) di negara Afganistan berdasarkan Pasal 110 ayat (1) Islamic Republic of Afghanistan (2004) merupakan manifestasi tertinggi dari rakyat Afganistan. Hal yang sama juga diatur dalam Pasal 25 Constitution of the Republic of China yang mengatur bahwa National Assembly melaksanakan hak politik atas nama seluruh rakyat. memiliki fungsi khusus yang dilakukan secara terus menerus, dan merupakan lembaga negara tertinggi 
(2) Memanggil kembali (recall) Presiden dan Wakil Presiden;

(3) Mengubah UUD;

(4) Memutuskan usulan untuk melakukan perubahan UUD yang diajukan di Legislative Yuan;

(5) Memutuskan pemakzulan terhadap Presiden atau Wakil Presiden;

(6) Memilih Presiden dan Wakil Presiden baru, dalam hal jabatan Presiden dan Wakil Presiden kosong. ${ }^{44}$

Berdasarkan pengaturan dalam Pasal 111 Constitution of the Islamic Republic of Afghanistan, maka kewenangan formal Grand Council (Loya Jirga) adalah sebagai berikut:

(1) Mengambil keputusan tentang hal-hal terkait dengan kemerdekaan, kedaulatan nasional, integritas wilayah, dan kepentingan tertinggi dari Negara;

(2) Mengubah UUD;

(3) Memutus pemakzulan presiden. ${ }^{45}$

Dari perbandingan dengan negara lain yang mengkonstruksikan fungsi khusus bagi kamar ketiga, dalam hal ini yang memiliki kesamaan dengan MPR adalah fungsi khusus untuk mengubah UUD dan memutus pemakzulan Presiden dan Wakil Presiden, maka dapat disimpulkan bahwa keberadaan MPR sebagai kamar ketiga dalam Parlemen R.I. bukan merupakan hal yang tidak lazim, walaupun kamar ketiga pada negara-negara yang disebutkan sebelumnya merupakan lembaga negara tertinggi dalam negara tersebut.

\section{Usulan Penguatan MPR Sebagai Lembaga Parlemen Dalam Sistem Ketatanegaraan di Indonesia}

Dalam Pasal 3 ayat 1 Perubahan Ketiga UUD 1945 diatur bahwa MPR berwenang mengubah dan menetapkan UUD. Sebagai lembaga yang memiliki kewenangan untuk mengubah dan menetapkan UUD, maka sudah seharusnya MPR juga merupakan lembaga yang paling berwenang untuk melakukan pengkajian terhadap UUD, sebab sebelum melakukan kegiatan mengubah kemudian menetapkan maka hal yang perlu dilakukan terlebih dahulu adalah

\footnotetext{
${ }^{44}$ Fatmawati, Op. Cit., hal. 220.

${ }^{45}$ Ibid., hal. 214-215.
} 
melakukan pengkajian-pengkajian terhadap materi muatan UUD 1945. Konsep ini yang digunakan oleh penyusun UUD 1945, dimana dikonstruksikan bahwa MPR terkait dengan UUD, melakukan kajian-kajian, dan jika perlu akan melakukan perubahan, sebagaimana dikemukakan oleh Soepomo, yaitu:

Kita harus mengadakan satu sistem. Segala sistem ada baik dan ada jeleknya. Tadi tentang presiden sama kabinet, sistem mana saja tidak sempurna, sistem kita pun, kalau kita cari ada aibnya, sebab kita manusia, dan tidak sempurna. Tetapi marilah kita menjalankan ini dan saban 5 tahun akan kita mengeritik diri - sendiri, artinya bagaimana haluan yang dijalankan, dibelakang itu. Kalau memang salah Undang - Undang Dasar bisa dirubah, kalau perlu malah sebelumnya 5 tahun. ${ }^{46}$

Sehingga kajian merupakan kegiatan MPR yang rutin, bukan jika akan melakukan amandemen baru dilakukan pengkajian.

Termasuk pula pengkajian yang dilakukan oleh MPR sebelum perubahan UUD 1945, adalah pengkajian terhadap haluan negara. Dalam Konstitusi RIS dan UUDS RI, tidak terdapat haluan negara yang disetujui oleh parlemen, akan tetapi dalam kedua UUD tersebut terdapat asas-asas dasar yang dijadikan dasar dalam penyelenggaraan negara. ${ }^{47}$ Salah satu pasal dari asas-asas dasar yang tercantum dalam kedua UUD tersebut, yaitu:

Penguasa memajukan kepastian dan jaminan sosial, teristimewa pemastian dan penjaminan syarat-syarat perburuhan yang baik, pencegahan dan pemberantasan pengangguran serta menyelenggarakan persediaan untuk hari tua dan pemeliharaan janda-janda dan anak yatim piatu. ${ }^{48}$

${ }^{46}$ A.B. Kusuma, Ibid., hal. 389. Lihat pula Saafroedin Bahar, Ananda B. Kusuma, Nannie Hudawati eds., Ibid., hal. 304.

47 Asas-asas dasar dalam Konstitusi RIS lihat Republik Indonesia Serikat, Keputusan Presiden tentang Mengumumkan Piagam Penandatanganan Konstitusi Republik Indonesia Serikat dan Konstitusi Republik Indonesia Serikat, Keppres No. 48, LN No. 3, LN Tahun 1950, Pasal 34-41. Asas-asas dasar dalam UUDS RI lihat dalam Republik Indonesia, Undang-Undang tentang Perubahan Konstitusi Sementara Republik Indonesia Serikat menjadi Undang-Undang Dasar Sementara Republik Indonesia, UU No. 7 Tahun 1950, LN. No. 56, LN Tahun 1950, TLN No. 37 , Pasal 35-43.

${ }^{48}$ Lihat Republik Indonesia Serikat, Keputusan Presiden tentang Mengumumkan Piagam Penandatanganan Konstitusi Republik Indonesia Serikat dan Konstitusi Republik Indonesia Serikat, 
Arahan dalam penyelenggaraan bernegara haruslah berpedoman pada asasasas dasar yang terdapat dalam UUD 1945, dan berbeda dengan Konstitusi RIS dan UUD RI yang mengatur lebih lengkap dan pada bab khusus berjudulkan Asas-Asas Dasar dalam kedua UUD tersebut, asas-asas dasar dalam UUD 1945 lebih sedikit dan tersebar pengaturannya dalam berbagai bab. Sebagai lembaga yang berwenang menetapkan dan mengubah UUD, maka MPR merupakan lembaga yang tepat untuk mengkaji dan menyusun berbagai asas-asas dasar yang terdapat dalam UUD 1945 untuk selanjutnya dijadikan arahan dalam penyelenggaraan bernegara.

Terdapat pendapat yang menyatakan bahwa dengan diaturnya UU Nomor 17 Tahun 2007 tentang Rencana Pembangunan Jangka Panjang Nasional 20052025 maka GBHN menjadi tidak diperlukan lagi. Hal tersebut tentu saja merupakan hal yang keliru karena perubahan UUD 1945 lah yang menyebabkan kewenangan menetapkan GBHN tidak lagi menjadi kewenangan MPR karena sudah tidak diatur dalam perubahan UUD 1945. Hal tersebut yang menjadi dasar "menimbang" butir a dalam UU tersebut. ${ }^{49}$

UU Nomor 17 Tahun 2007 tentang Rencana Pembangunan Jangka Panjang Nasional 2005-2025 inilah yang perlu didiskusikan lebih lanjut. Dalam Pasal 3 UU Nomor 17 Tahun 2007 tentang Rencana Pembangunan Jangka Panjang Nasional 2005-2025 diatur bahwa:

RPJP Nasional merupakan penjabaran dari tujuan dibentuknya Pemerintahan Negara Indonesia yang tercantum dalam Pembukaan Undang-Undang Dasar Negara Republik Indonesia Tahun 1945, yaitu untuk melindungi segenap bangsa dan seluruh tumpah darah Indonesia, memajukan kesejahteraan umum, mencerdaskan kehidupan bangsa, dan ikut melaksanakan ketertiban dunia yang berdasarkan kemerdekaan, perdamaian abadi, dan keadilan sosial dalam bentuk rumusan visi, misi dan arah Pembangunan Nasional. ${ }^{50}$

Pasal 35. Lihat Republik Indonesia, Undang-Undang tentang Perubahan Konstitusi Sementara Republik Indonesia Serikat menjadi Undang-Undang Dasar Sementara Republik Indonesia, Pasal 36.

49 Republik Indonesia, Undang-Undang tentang Rencana Pembangunan Jangka Panjang Nasional 2005-2025, UU Nomor 17, LN Nomor 33 Tahun 2007, TLN Nomor 4700, bagian Menimbang.

${ }^{50}$ Ibid., Pasal 3. 
Pasal tersebut mengatur bahwa RPJPN merupakan penjabaran dari tujuan dibentuknya Pemerintahan Negara Indonesia yang tercantum dalam Pembukaan UUD 1945, tidak mencantumkan bahwa RPJPN juga merupakan penjabaran asas-asas yang ada pada pasal-pasal dalam UUD 1945, seperti antara lain asas kekeluargaan dan kewajiban pemerintah untuk menguasai bumi, air, dan kekayaan alam yang terkandung didalamnya untuk sebesarbesarnya kemakmuran rakyat.

Dalam Lampiran UU Nomor 17 Tahun 2007 tentang Rencana Pembangunan Jangka Panjang Nasional 2005-2025, terdapat beberapa hal yang tidak sesuai dengan asas-asas dalam UUD 1945, terutama dalam bidang keadilan sosial. Dalam Bab III tentang Visi dan Misi Pembangunan Nasional 2005-2025 bagian B (Memperkuat Perekonomian Domestik dengan Orientasi dan Berdaya Saing Global) angka 10, dinyatakan bahwa:

Peranan pemerintah yang efektif dan optimal diwujudkan sebagai fasilitator, regulator, sekaligus sebagai katalisator pembangunan di berbagai tingkat guna efisiensi dan efektivitas pelayanan publik, terciptanya lingkungan usaha yang kondusif dan berdaya saing, dan terjaganya keberlangsungan mekanisme pasar. ${ }^{51}$

Sangat menarik apa yang dikemukakan oleh RPJPN butir 10 di atas, karena peranan pemerintah salah satunya adalah menjaga keberlangsungan mekanisme pasar, sedangkan dalam asas kekeluargaan yang dikemukakan oleh founding fathers dan merupakan salah satu pasal yang tidak diubah (Pasal 33 ayat (1)) ketika perubahan UUD 1945, asas kekeluargaan berarti rakyat yang berdaulat di bidang ekonomi, ${ }^{52}$ sehingga hal yang minimal adalah sebagaimana diatur dalam Pasal 33 ayat (4) Perubahan Keempat, pemerintah seharusnya menjaga keseimbangan dan kemajuan ekonomi nasional. ${ }^{53}$ Menurut Jimly Asshiddiqie, pencantuman prinsip-prinsip kebersamaan, efisiensi, berkeadilan,

\footnotetext{
${ }^{51}$ Ibid., bagian lampiran, hal. 49.
}

52 Lihat Jimly Asshiddiqie, "Konsolidasi Naskah UUD 1945 Setelah Perubahan Keempat", (Jakarta: Pusat Studi Hukum Tata Negara, 2002), hal. 56.

${ }^{53}$ Lihat Republik Indonesia, Perubahan Keempat Undang-Undang Dasar Negara Republik Indonesia Tahun 1945, LN No. 14, LN Tahun 2006, Pasal 33 ayat (4), yang mengatur sebagai berikut: "Perekonomian nasional diselenggarakan berdasar atas demokrasi ekonomi dengan prinsip kebersamaan, efisiensi, berkeadilan, berkelanjutan, berwawasan lingkungan, kemandirian, serta dengan menjaga keseimbangan kemajuan dan kesatuan ekonomi nasional". 
berkelanjutan, berwawasan lingkungan, kemandirian, serta dengan menjaga keseimbangan kemajuan dan kesatuan ekonomi nasional dalam ayat ini merupakan jalan tengah dalam melengkapi ketentuan asas kekeluargaan, ${ }^{54}$ sehingga jika pemerintah berperan menjaga keberlangsungan mekanisme pasar, tanpa mengatur tentang penekanan kedaulatan rakyat, tentunya akan sangat jauh dari asas kekeluargaan yang dimaksud dalam UUD 1945.

Hal lain yang perlu didiskusikan bersama terkait pembentukan UU Nomor 17 Tahun 2007 tentang Rencana Pembangunan Jangka Panjang Nasional 20052025 ini adalah dalam pembentukannya tidak melibatkan Dewan Perwakilan Daerah yang merupakan wakil daerah.

Sebagaimana dikemukakan oleh Tsebelis dan Money, kamar kedua memiliki justifikasi dari segi efisiensi, ${ }^{55}$ akan tetapi hal tersebut tidak dapat ditemukan dalam parlemen RI karena berbeda dengan kamar kedua di berbagai negara umumnya, DPD sebagai kamar kedua (second chambers) memiliki kewenangan yang terbatas dikaitkan dengan pembentukan UU. Dalam sistem bikameral dari 20 negara yang kedua kamarnya memiliki fungsi legislasi, pembatasan kewenangan terhadap kamar kedua adalah dalam hal pengusulan $\mathrm{UU},{ }^{56}$ akan tetapi hampir seluruh kamar kedua memiliki hak membahas dan hak veto. DPD hanya memiliki hak membahas, dimana pembahasan juga tidak dilakukan dalam conference committee, akan tetapi anggota DPD dibatasi 1/3 anggota DPR. Dari penelitian penulis pada 26 negara yang dibahas, jumlah utusan dari kamar-kamar yang tidak seimbang tersebut selain pada DPD adalah pada President's Council dalam Constitutions of the Republic of South Africa Act 110 of 1983 yang mengatur bahwa utusan dari kamar yang anggotanya merupakan wakil dari warga negara berkulit putih lebih banyak dari utusan dari kamar yang anggotanya merupakan wakil dari warga negara berkulit berwarna dan wakil dari warga negara bangsa India. ${ }^{57}$

\section{${ }^{54}$ Asshiddiqie, Op. Cit., hal. 57.}

55 Lihat George Tsebelis dan Jeannette Money, "Bicameralism", (London: Cambridge University Press, 1997), hal 37-42.

${ }^{56}$ People's Democratic Republic of Algeria, Kingdom of the Netherlands, dan United Kingdom of Great Britain and Northern Ireland.

${ }^{57}$ Fatmawati, "Struktur dan Fungsi Legislasi Parlemen dengan Sistem Multikameral: Studi Perbandingan antara Indonesia dan Berbagai Negara", (Jakarta: UI Press, 2010), hal. 355. 
Pembahasan DPD dengan DPR tersebut juga tidak terlalu signifikan karena UUD 1945 mengatur bahwa RUU hanya dapat disahkan jika dibahas dan disetujui bersama antara DPR dan Presiden. ${ }^{58}$

Bila dibandingkan dengan kamar kedua pada negara Democratic Republic of Ethiopia dan negara Arab Republic of Egypt, maka DPD masih lebih baik karena kamar kedua pada kedua negara tersebut tidak memiliki kewenangan membentuk UU, akan tetapi jika dibandingkan dengan 11 negara yang juga dikategorikan sebagai weak bicameralism, maka kewenangan DPD sangat terbatas karena ke-11 negara tersebut memiliki kewenangan mengusulkan, membahas, dan menolak RUU, walaupun penolakan tersebut dapat diabaikan oleh kamar pertama, kecuali pada negara Kingdom of Netherlands dan United Kingdom of Great Britain and Northern Ireland yang tidak memiliki kewenangan mengusulkan. ${ }^{59}$

\section{Penutup}

Sebagai penutup, penulis ingin mengemukakan bahwa perubahan UUD bukan merupakan hal yang luar biasa, sehingga perlu dilakukan pengkajian terus menerus terhadap UUD, bahkan seperti yang dikemukakan Soepomo, jika perlu dalam kurun waktu kurang dari 5 tahun, jika ada kekurangan, maka pembentuk UUD akan melakukan perubahan untuk melakukan perbaikan terhadap kekurangan yang tersebut. Akan tetapi, dalam hal penguatan MPR yang diusulkan penulis dalam makalah singkat ini, penguatan MPR dilakukan tanpa melalui perubahan UUD. Penguatan MPR sebagaimana penulis usulkan menjadi relevan mengingat sebagai lembaga negara yang berwenang mengubah dan menetapkan UUD maka MPR berwenang untuk mengkaji dan menemukan berbagai asas-asas dasar yang terkandung dalam UUD 1945 untuk dijadikan pedoman dalam penyelenggaraan bernegara. Hal ini menjadi perlu agar tidak lagi terjadi seperti sekarang ini dimana masing-masing lembaga negara membuat arahan penyelenggaraan lembaganya

${ }^{58}$ Lihat Republik Indonesia, Perubahan Pertama Undang-Undang Dasar Negara Republik Indonesia Tahun 1945, LN No. 14, LN Tahun 2006, Pasal 20 ayat (2), (3), (4) dan (5).

${ }^{59}$ Lihat Fatmawati, Op. Cit., hal. 356. Negara lainnya yang Kamar Keduanya juga tidak memiliki kewenangan mengusulkan adalah People's Democratic Republic of Algeria, akan tetapi negara ini masuk dalam kriteria strong bicameralism karena secara umum, kewenangan Kamar Kedua hamper sama dengan Kamar Pertama. 
berdasarkan pemahamannya masing-masing tanpa ada arahan yang didasarkan pada UUD 1945. 


\section{Daftar Pustaka}

\section{Buku}

Alrasid, Harun, Naskah UUD 1945 Sesudah Empat Kali Diubah. Jakarta: UI-Press, 2003.

Majelis Permusyawaratan Rakyat (Pelaku Kedaulatan Rakyat), Dalam A. Muhammad Asrun, ed. 70 Tahun Ismail Suny Bergelut dengan Ilmu, Berkiprah dalam Politik, Jakarta: Pustaka Sinar Harapan, 2000.

Asshiddiqie, Jimly. Pergumulan Peran Pemerintah dan Parlemen dalam Sejarah: Telaah Perbandingan Komnstitusi Berbagai Negara, Jakarta: UI Press, 1986.

. Konsolidasi Naskah UUD 1945 Setelah Perubahan Keempat, Jakarta: Pusat Studi Hukum Tata Negara, 2002.

. et al., ed. Kompilasi Konstitusi Sedunia, Buku 1. Jakarta: Pusat Penelitian dan Pengkajian Sekretariat Jenderal dan Kepaniteraan Mahkamah Konstitusi Republik Indonesia, 2005.

. et al., ed.. Kompilasi Konstitusi Sedunia, Buku 2. Jakarta: Pusat Penelitian dan Pengkajian Sekretariat Jenderal dan Kepaniteraan Mahkamah Konstitusi Republik Indonesia, 2005.

. Konstitusi dan Konstitusionalisme Indonesia. Ed. Revisi, Cet. 3. Jakarta: Setjen dan Kepaniteraan Mahkamah Konstitusi RI, 2006.

Bahar, Saafroedin, Ananda B. Kusuma, Nannie Hudawati eds. Risalah Sidang Badan Penyelenggara Usaha Persiapan Kemerdekaan Indonesia (BPUPKI)-Panitia Persiapan Kemerdekaan Indonesia (PPKI) 28 Mei 1945-22 Agustus 1945, Ed. III. Cet. 2. Jakarta: Sekretariat Negara R.I., 1995.

Fatmawati. Struktur dan Fungsi Legislasi Parlemen dengan Sistem Multikameral: Studi Perbandingan antara Indonesia dan Berbagai Negara, Jakarta: UI Press, 2010.

Friedrich, Carl J, Constitutional Government and Democracy Theory and Practice in Europe and America, Rev. Ed. Boston: Ginn and Company, 1949.

Hook, Glenn D dan Gavan Mc Cormack. Japan's Contested Constitution: Document and Analysis, London: Routledge, 2001. 
Inter Parliamentary Union. Parliaments: A Comparative Study on the Structure and Functioning of Representative Institutions in Fourty-One Countries, London: Cassell and Company Ltd, 1962.

Inter Parliamentary Union. Parliaments of the World: A Comparative Reverence Compendium, $2^{\text {nd }}$ ed. Vol. II. New York: Inter Parliamentary Union, 1986.

Kusuma, A.B. Lahirnya Undang-Undang Dasar 1945 (Memuat Salinan Dokumen Otentik Badan Oentoek Menyelidiki Oesaha2 Persiapan Kemerdekaan), .Jakarta: Badan Penerbit Fakultas Hukum UI, 2004.

Lijphart, Arend. Democracy: Patterns of Majoritarian and Consensus Government in Twenty-One Countries, New Haven and London: Yale University Press, 1984.

Patterns of Democracy: Government Forms and Performance in ThirtySix Countries, New Haven and London: Yale University, 1999.

. ed. Parliamentary versus Presidensial Government, Reprinted. New York: Oxford University Press, 2004.

Locke, John. Two Treatises of Government (In the Former, The False Principles and Foundation of Sir Robert Filmer, and His Followers, Are Detected and Overthrown: The Latter, Is an Essay Concerning the Original. Extent, and End, of Civil Government). In Ten Volume, Vol. V. London: Printed for Thomas Tegg; W. Sharpe and Son; G. Offor; G. and J. Robinson; J. Evans and Co.; Also R. Griffin and Co. Glasgow; and J. Gumming, Dublin, 1823.

Manan, Bagir. DPR, DPD dan MPR dalam UUD 1945 Baru, Cet. 2. Yogyakarta: FH UII Press, 2004.

Manuel, Paul Christopher dan Anne Maria Camissa. Checks and Balances? How a Parliamentary System Could Change American Politics, United States of America: Westview Press, 1999.

Montesquieu, L'Esprit des Lois, atau The Spirit of Laws. Trans. by Thomas Nugent tahun 1752. Rev. by J.V. Prichard. London: G. Bell and Sons, Ltd., 1914.

Pringgodigdo, A.G. Sedjarah Singkat Berdirinja Negara Republik Indonesia, Cet I. Surabaya: N.V. Pustaka Indonesia, 1958.

Sekretariat Jenderal MPR-RI. Panduan Dalam Memasyarakatkan Undang-Undang Dasar Negara Republik Indonesia Tahun 1945: Latar Belakang, Proses, dan Hasil Perubahan Undang-Undang Dasar Negara Republik Indonesia Tahun 
1945 Sesuai dengan Urutan Bab, Pasal, dan Ayat, Jakarta: Sekretariat Jenderal MPR-RI, 2007.

Tsebelis, George dan Jeannette Money. Bicameralism, Cambridge: Cambridge University Press, 1997.

Wheare, K.C. Legislatures, London: Oxford University Press, 1967.

\section{Makalah dan Artikel}

Kusuma, Ananda B. "Presidensialisme ala Indonesia." Disampaikan dalam "Diskusi Publik Wacana Amandemen UUD 1945" yang diselenggarakan oleh Komisi Hukum Nasional RI, Hotel Millenium, 15 Mei 2008.

\section{Compact Disc}

Sekretariat Jenderal MPR-RI. Risalah Rapat Ke-1 Panitia Ad Hock III BP MPR 7 Oktober 1999. Nomor MJ 230/3/99.

. Risalah Rapat Ke-2 Panitia Ad Hock III BP MPR 8 Oktober 1999. Nomor MJ 230/5/99.

. Risalah Rapat Ke-4 Panitia Ad Hock III BP MPR 10 Oktober 1999. Nomor MJ 230/9/99.

. Risalah Rapat Ke-6 Panitia Ad Hock III BP MPR 13 Oktober 1999. Nomor MJ 230/13/99. . Risalah Rapat Ke-8 BP MPR 14 Desember 2000.

. Risalah Rapat Ke-10 Panitia Ad Hock I BP MPR 17 Desember 2000.

. Risalah Rapat Ke-51 Panitia Ad Hock I BP MPR 29 Juli 2000.

. Risalah Rapat Pleno Ke-11 Panitia Ad Hock I BP MPR 20 Maret 2001. Nomor MJ 230/11/2001.

\section{Internet}

"Constitution of the People's Republic of China", <http://www.usconstitution.net/ china.html>, diakses tanggal 24 Agustus 2009. 
"Constitutions of the Republic of South Africa Act 110 of 1983", $<$ http://www.sahistory.org.za/pages/sources/docs/1983-constitution.htm>, diakses tanggal 4 Juli 20010,

"Taiwan Constitution", <http://wwwoefre.unibe/icl/>, diakses tanggal 19 November 2010.

"Taiwan-Constitution -- Additional Articles", <http://wwwoefre.unibe/icl/>, diakses tanggal 19 November 2010.

The Constitution of the Kingdom of the Netherlands 2002, Published by the Ministry of the Interior and Kingdom Relations, Constitutional Affairs and Legislation Department, in collaboration with the Translation Department of the Ministry of Foreign Affairs, <www.minbzk.nl>, diakses tanggal 8 Agustus 2010.

"The Constitution of The Socialist Federal Republic Of Yugoslavia", $<$ http://www.worldstatemen.org/Yugoslavia_1963.doc $>$, diakses tanggal 24 Agustus 2010.

"United Kingdom-"Constitution", <http://www.oefre.unibe.ch/law/icl/>, diakses tanggal 18 Juli 2010.

\section{Peraturan Perundang-Undangan}

Republik Indonesia. Keputusan Presiden mengenai Dekrit Presiden Republik Indonesia/Panglima Tertinggi Angkatan Perang tentang Kembali Kepada Undang-Undang Dasar 1945. Keppres No. 150. LN No. 75. LN Tahun 1959.

Republik Indonesia Serikat. Keputusan Presiden tentang Mengumumkan Piagam Penandatanganan Konstitusi Republik Indonesia Serikat dan Konstitusi Republik Indonesia Serikat. Keppres No. 48. LN No. 3. LN Tahun 1950

. Undang-Undang tentang Perubahan Konstitusi Sementara Republik Indonesia Serikat menjadi Undang-Undang Dasar Sementara Republik Indonesia. UU No. 7 Tahun 1950. LN. No. 56. LN Tahun 1950. TLN No. 37.

Republik Indonesia. Perubahan Pertama Undang-Undang Dasar Negara Republik Indonesia Tahun 1945. LN No. 11. LN Tahun 2006.

.. Perubahan Kedua Undang-Undang Dasar Negara Republik Indonesia Tahun 1945. LN No. 12. LN Tahun 2006. 
Perubahan Ketiga Undang-Undang Dasar Negara Republik Indonesia Tahun 1945. LN No. 13. LN Tahun 2006.

Perubahan Keempat Undang-Undang Dasar Negara Republik Indonesia Tahun 1945. LN No. 14. LN Tahun 2006.

. Undang-Undang tentang Rencana Pembangunan Jangka Panjang Nasional 2005-2025. UU Nomor 17. LN Nomor 33 Tahun 2007. TLN Nomor 4700 . 